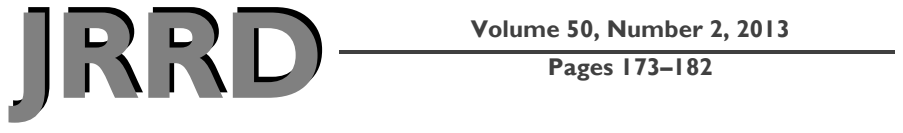

\section{Major traumatic limb loss among women veterans and servicemembers}

\author{
Jodie G. Katon, PhD; ${ }^{1-2 *}$ Gayle E. Reiber, $\mathbf{P h D}^{1-3}$ \\ ${ }^{1}$ Department of Veterans Affairs Puget Sound Health Care System, Seattle, WA; Departments of ${ }^{2}$ Health Services and \\ ${ }^{3}$ Epidemiology, University of Washington School of Public Health, Seattle, WA
}

\begin{abstract}
The number of women veterans is rapidly growing, and little is known regarding the health and healthcare needs of women veterans with traumatic limb loss. The objective of this study was to summarize physical and mental health conditions and rates of prosthetic prescriptions among women servicemembers and veterans with major traumatic limb loss. Researchers and clinicians who administered the Survey for Prosthetic Use contacted and enrolled 283 servicemembers and veterans of Operation Iraqi Freedom/Operation Enduring Freedom with major traumatic limb loss. Participants provided information on health status; comorbidities; other combat injuries; and prosthetic device use, rejection, and replacement. Of the 283 veterans, 9 (3\%) were women. Compared with men, women reported more than a threefold higher prevalence of migraine ( $67 \%$ vs $20 \%, p=0.001$ ). Compared with men, women received 0.42 more prostheses per year, rejected 0.11 more prostheses per year, but replaced 0.18 fewer prostheses per year. With the exception of migraine headaches, men and women servicemembers and veterans with major traumatic limb loss report similarly high prevalence of physical and mental health conditions. Women report higher rates of prosthesis receipt and rejection and lower rates of prosthesis replacement than men. These findings highlight some potential issues specific to women veterans that may require additional clinical attention.
\end{abstract}

Key words: headaches, health, health status, limb loss, mental health, migraines, OIF/OEF, women servicemembers, women veterans, wounded servicemembers.

\section{INTRODUCTION}

One of the top priorities of the Department of Veterans Affairs (VA) is the provision of care for Operation Iraqi Freedom/Operation Enduring Freedom (OIF/OEF) veterans. As of January 2011, more than 1,164 servicemembers from OIF/OEF sustained at least one major limb loss [1]. Unlike the civilian population, the majority of servicemembers who experience limb loss are less than $35 \mathrm{yr}$ old and lose a limb as a result of traumatic injuries rather than an underlying chronic condition such as diabetes or vascular disease [2]. Restoring the current cohort of servicemembers and veterans with traumatic limb loss to the highest possible level of physical function is a top priority and has led to a paradigm shift at both the Department of Defense (DOD) [1] and VA [3]. Rehabilitation following limb loss is a complex process involving physical and psychological components [1,4].

Women veterans from OIF/OEF are currently the fastest growing group of new VA healthcare users [5]. Although women represent a small percentage of servicemembers and veterans with traumatic limb loss, little is known regarding their potentially unique health and healthcare needs. Previous research was limited to civilian populations and yielded mixed results regarding sex differences in the health and healthcare needs of men and

\footnotetext{
Abbreviations: DOD $=$ Department of Defense, OIF/OEF = Operation Iraqi Freedom/Operation Enduring Freedom, PTSD = posttraumatic stress disorder, SF-36 $=$ 36-Item Short Form Health Survey, TBI = traumatic brain injury, VA = Department of Veterans Affairs.

*Address all correspondence to Jodie G. Katon, PhD; VA Medical Center, 1660 S. Columbian Way, S-152, Seattle, WA 98108; 206-277-1843; fax: 206-764-2935.

Email: jodie.katon@va.gov

http://dx.doi.org/10.1682/JRRD.2012.01.0007
} 
women with limb loss. Compared with men, women may experience overall higher pain intensity and interference with activities of daily living after limb loss [6] and be less likely to be successfully fitted with a prosthesis before discharge [7]. The results have been inconclusive regarding the effect of sex on psychosocial outcomes of limb loss, with the majority of studies reporting no difference in outcomes by sex [4,8-9]. However, there is some evidence that following limb loss, women are more likely to experience depression than men [10] and have greater difficulty with emotional adaptation to role changes [1112]. There is also limited evidence that compared with men, women with limb loss have a higher degree of body-image anxiety [13]; body-image anxiety may also be associated with lower levels of prosthesis satisfaction [14]. Additionally, women may have different requirements than men for prostheses because of different patterns of footwear usage [15].

A primary limitation of the majority of prior studies regarding sex differences among individuals experiencing limb loss is the focus on older civilian patients who experienced limb loss as a consequence of chronic disease. Thus, the findings of these earlier studies may not be generalizable to women OIF/OEF servicemembers and veterans, who are younger and experience traumatic rather than disease-related limb loss. Therefore, the objective of this study was to report on the health status, prevalence of comorbid health conditions, and indicators of prosthetic use among men and women OIF/OEF servicemembers and veterans with traumatic limb loss.

\section{METHODS}

We used existing data from the Survey for Prosthetic Use, which was developed by a group of rehabilitation and surgery clinicians and researchers using conventional survey methodology to address key issues for veterans and servicemembers with major traumatic upper- and lower-limb loss [1]. The survey included OIF/OEF servicemembers (January 2000 to January 2008) with major traumatic limb loss who were at least $1 \mathrm{yr}$ from their amputation. By requiring that participants be at least $1 \mathrm{yr}$ from their amputation, we ensured that participants were far enough into the rehabilitation phase to be able to reflect on their prosthetic experiences. Exclusion criteria included cognitively unable to respond to the survey, lack of valid contact information, amputation only to the fin- gers or toes, or death. The survey collected detailed information on demographic characteristics, health status and comorbidities, site and degree of limb loss, other combatassociated injuries, and use of prosthetic and assistive devices.

Demographic variables included sex, age at time of survey, race/ethnicity, marital status, having children, and current employment in military or nonmilitary positions. Self-reported health status information was collected using questions on the 36-Item Short Form Health Survey (SF-36) [16-17]. Health status was categorized as either (1) excellent, very good, or good or (2) fair or poor. The presence or absence of 15 comorbid conditions, including arthritis, migraine, chronic back pain, phantom limb pain, residual limb pain, traumatic brain injury (TBI), depression, and posttraumatic stress disorder (PTSD), was assessed by self-report. A variable for total pain summary was created by calculating the sum of three dichotomous pain questions (chronic back pain, phantom limb pain, and residual limb pain), for which the minimum score was 0 (chronic back pain, phantom limb pain, and residual limb pain all absent) and the maximum score was 3 (chronic back pain, phantom limb pain, and residual limb pain all present). Differences by sex in the summary measures of pain and prevalence of depression and PTSD were examined for the total sample and stratified by current prosthesis use.

Site and level of limb loss was grouped into three categories: unilateral upper-limb loss, unilateral lowerlimb loss, and multiple limb loss. Participants were also asked about the presence of other combat injures, including injury to limb(s) without limb loss, head injury, eye injury, hearing loss, chest injury, abdominal injury, burns, and other combat injuries.

Participants were asked about the number and type of prosthetic devices ever and currently used, including prostheses received in their first year after limb loss and prostheses received from $1 \mathrm{yr}$ after limb loss to the present. Prostheses were grouped into three categories: myoelectric/advanced devices, mechanical or body-powered devices, and sports or specialty devices [1]. Participants also reported the number and type of prostheses they rejected, the number and type of prosthetic devices they wore out, and the average time to replacement. We computed annual rates for prosthetic device receipt, replacement, and rejection from the time of limb loss to the survey date by dividing the appropriate numerator (number 
of prostheses received, rejected, or replaced) by years since limb loss.

We compared health status, prevalence of comorbidities, distribution and degree of limb loss, and combatassociated injuries between men and women. Annual rates of prosthetic device receipt, replacement, and rejection were compared between men and women. Categorical variables were compared using the chi-square test or the Fisher exact test when cell sizes were $\leq 5$, and continuous variables were compared using the Student $t$-test. Statistical significance was defined at the two-sided alpha level of $p \leq 0.05$.

\section{RESULTS}

Of the 541 identified OIF/OEF service members with traumatic limb loss, 482 were contacted. Of those contacted, 283 were enrolled, including 9 women (Figure 1). Table 1 illustrates the demographic and lifestyle characteristics of the total sample and by sex. The mean age at the time of the survey was $29 \mathrm{yr}$, and the majority of participants were white (73\%), married (61\%), medically discharged (58\%), and currently employed (53\%). Comparing demographic and lifestyle characteristics of women and men participants, we found that women were more likely to be nonwhite, less likely to have children, and more likely to be employed.

Table 2 shows the health status and prevalence of comorbidities for the total sample and by sex. While the majority of participants reported excellent, very good, or good health status (86\%), there was a high overall prevalence of persistent physical and mental health conditions, including arthritis (26\%), phantom limb pain (76\%), residual limb pain (63\%), TBI (34\%), depression (24\%), and PTSD (59\%). With the exception of migraine, the prevalence of comorbidities did not differ by sex. Compared with men, women had more than a threefold higher reported prevalence of migraines $(67 \%$ vs $20 \%, p=$ 0.001). Mean pain scores and prevalence of depression and PTSD were higher among those not currently using a prosthesis than those currently using a prosthesis, but within these groups mean pain scores did not differ by sex.

Compared with men, a smaller proportion of women experienced unilateral lower-limb loss and a larger proportion experienced multiple limb loss (Figure 2). Table 3 shows the prevalence of other combat-related injuries for men and women. The prevalence of other combat-

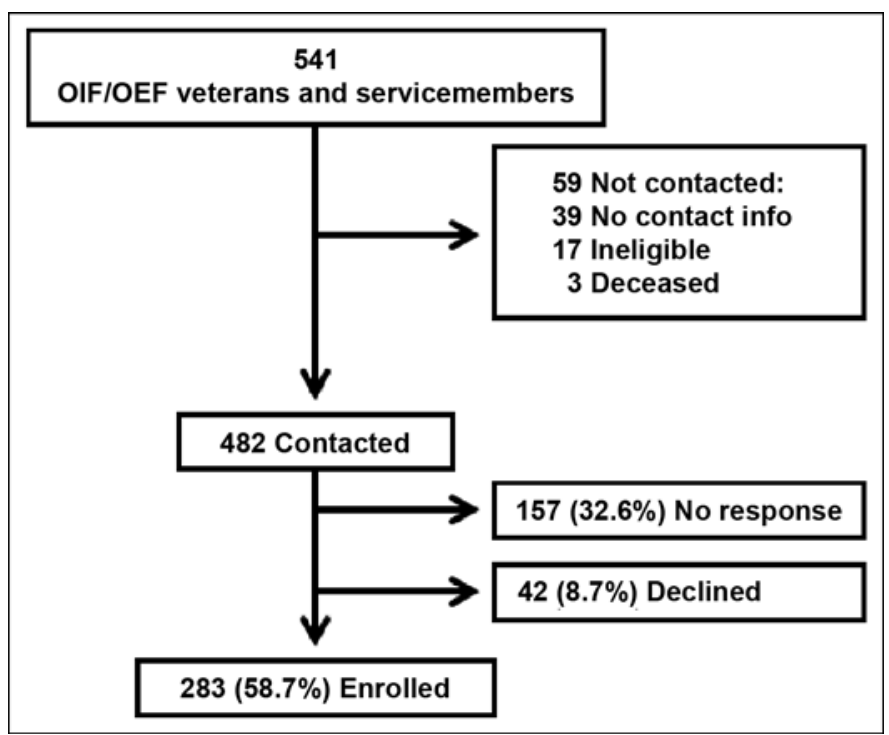

Figure 1.

Survey enrollment for Operation Iraqi Freedom/Operation Enduring Freedom (OIF/OEF) survey participants with traumatic limb loss.

related injuries did not differ by sex except for hearing loss, with women reporting fivefold lower prevalence of hearing loss than men ( $49 \%$ vs $11 \%, p=0.03$ ).

Table 4 summarizes the types of prosthetic devices used by men and women and the annual rates of prosthetic device use, rejection, and replacement. Compared with men, women received a greater number of all types of prosthetic devices (myoelectric, mechanical, and sports/specialty). Specifically, on average, women received 0.42 more prostheses per year and rejected 0.11 more prostheses per year than men. However, women replaced 0.18 fewer prostheses per year than men.

\section{DISCUSSION}

Despite the small number of women with traumatic limb loss, this study identified potentially important differences between men and women servicemembers and veterans with traumatic limb loss. Compared with men, women were more likely to report having migraine headaches and had a lower prevalence of hearing loss related to their combat injuries. With respect to prosthesis prescription, women had higher annual rates of receipt and rejection but lower annual rates of replacement than men. 
JRRD, Volume 50, Number 2, 2013

Table 1.

Demographic characteristics of Operation Iraqi Freedom/Operation Enduring Freedom survey participants by participant sex. Data presented as percent unless otherwise noted.

\begin{tabular}{lccc}
\hline \multicolumn{1}{c}{ Characteristic } & Total $(\boldsymbol{n}=\mathbf{2 8 3})$ & Women $(\boldsymbol{n}=\mathbf{9})$ & Men $(\boldsymbol{n}=\mathbf{2 7 4})$ \\
\hline Age, yr (mean \pm SD) & $29 \pm 5.8$ & $29 \pm 5.6$ & $29 \pm 5.8$ \\
Race/Ethnicity & & 56 & 74 \\
Caucasian & 73 & 33 & 9 \\
African American & 10 & 0 & 9 \\
Hispanic/Latino & 9 & 11 & 5 \\
Asian & 1 & 0 & 1 \\
American Indian/Alaska Native & 5 & 0 & 1 \\
Native Hawaiian/Pacific Islander & 1 & 0 & 61 \\
Other & 1 & 56 & 0 \\
Marital Status & & 56 & 30 \\
Married/Living Together & 61 & 0 & 50 \\
Divorced/Separated & 9 & 0 & 20 \\
Widowed & 0 & 44 & 9 \\
Never Married & 30 & 11 & 58 \\
Have Children & 48 & & 10 \\
Current Military Status & & 22 & 3 \\
Active Military & 21 & 0 & 3 \\
In Rehabilitation & 9 & 67 & 53 \\
Medical Discharge & 58 & 0 & 23 \\
Discharge & 10 & 11 & \\
National Guard/Reserves & 3 & 67 & \\
Current Employment & & 22 & \\
Employed & 53 & 11 & \\
Student & 23 & & \\
Retired (not employed after amputation) & 21 & & \\
Other & 3 & & \\
SD standard deviation. & & & \\
\hline \hline
\end{tabular}

Both men and women participants reported high health status despite the high prevalence of comorbidities. The high self-reported health status of servicemembers and veterans with traumatic limb loss has been described elsewhere [1] and is consistent with current theories of psychosocial reactions to traumatic limb loss [18].

Combined, men and women who used prostheses had better mental health than those not using prostheses. This is consistent with literature indicating higher levels of depression among individuals with limb loss who do not use prostheses [19]. While prosthesis use is associated with improved mental and physical health [19], underlying physical and mental health may also influence an individual's ability to use a prosthesis and persist through the period of adaptation to a prosthesis [20]. Whether or not the improvement in mental health associated with prosthesis use occurs through different mechanisms in men and women is still poorly understood.

Prior studies in the general U.S. population found that approximately 18 percent of women and 6 percent of men report migraine [21-22], and a survey of men and women recently deployed in OIF found that 25 percent of women and 17 percent of men met modified International Classification of Headache Disorders criteria for migraine [23]. The cumulative evidence from human and animal studies suggests that sex hormones play a key role in explaining the difference in prevalence of migraine between men and women [24]. Additionally, women experience migraines with more frequent [21], prolonged [25], and painful headaches [26] than men. While we observed a similar difference in prevalence of migraine by sex, the prevalence of migraine among both adult men 
Table 2.

Current health status and comorbidities in Operation Iraqi Freedom/Operation Enduring Freedom servicemembers and veterans by sex. Data presented as percent unless otherwise noted.

\begin{tabular}{|c|c|c|c|c|}
\hline Condition & Total $(n=283)$ & Women $(n=9)$ & $\operatorname{Men}(n=274)$ & $p$-Value \\
\hline Excellent/Very Good/Good Health Status & 86 & 89 & 85 & 0.77 \\
\hline Arthritis & 26 & 11 & 26 & 0.31 \\
\hline Chronic Back Pain & 42 & 56 & 42 & 0.41 \\
\hline Phantom Limb Pain & 76 & 78 & 76 & 0.90 \\
\hline Residual Limb Pain & 63 & 67 & 63 & 0.81 \\
\hline Currently Using Prosthesis ${ }^{*}$ (mean \pm SD) & $1.79 \pm 0.93$ & $1.88 \pm 1.36$ & $1.78 \pm 0.91$ & 0.78 \\
\hline Not Currently Using Prosthesis* (mean \pm SD) & $2.04 \pm 1.06$ & 3.00 & $2.00 \pm 1.06$ & - \\
\hline Traumatic Brain Injury & 34 & 33 & 34 & 0.97 \\
\hline Depression & 24 & 22 & 24 & 0.90 \\
\hline Currently Using Prosthesis & 23 & 25 & 23 & 0.89 \\
\hline Not Currently Using Prosthesis & 63 & 0 & 65 & - \\
\hline
\end{tabular}

and women in our study was higher than that reported in the U.S. population [21-22] or among servicemembers without limb loss [23]. Thus, while our findings mirror those in the general population with respect to sex differences, they indicate a potentially much higher overall burden of migraine for both men and women with traumatic limb loss, which may in part be because of the high prevalence of mental health conditions associated with increased risk of migraine [27-28].

Alternatively, self-report of migraine was not based on meeting any specific criteria, and if those reporting migraine included individuals with headaches that resembled but did not meet clinical criteria for true migraine, then the prevalence of migraine in our study closely resembles the combined prevalence of migraine and possible migraine in the survey by Theeler et al. of recently deployed men and women [23]. Additionally, the high prevalence of migraine is potentially related to high rates of pain medication use and resultant rebound or medication-induced headaches [29]; however, we lacked the data to test this hypothesis.

Both men and women in our study reported similarly high levels of phantom and residual limb pain. Previously, Kooijman et al. reported in a group of 72 individuals with upper-limb amputation that there was no statistically significant association between sex and phantom limb pain $(p=0.20)$ [30]. Similarly, Hirsh et al. reported in an analysis of 335 individuals with limb loss that while men reported a higher prevalence of phantom limb pain than women ( $86 \%$ vs $77 \%$ ), this difference was not statistically significant after accounting for the cause of limb loss [6]. All participants in our study experienced limb loss as a result of trauma, and similar to previous studies [6,30], we did not detect any differences in reported pain by sex. Importantly, we did not have information regarding pain intensity, interference, or coping, which have been found to differ by sex among those with limb loss [6].

Men and women in our study reported a similarly high prevalence of mental health conditions, including depression and PTSD. The literature is mixed with respect to sex differences in mental health following limb loss. In a sample of 72 patients with limb loss, Shukla et al. reported that patient sex was not associated with the presence of psychiatric symptoms [8]. Similarly, Rybarczyk et al. found no association between sex and psychological well-being among 89 individuals with leg amputations [9]. However, Pezzin et al. found that compared with men, women were more likely to have a low score on the Role Emotional component scale of the SF-36 at an average 


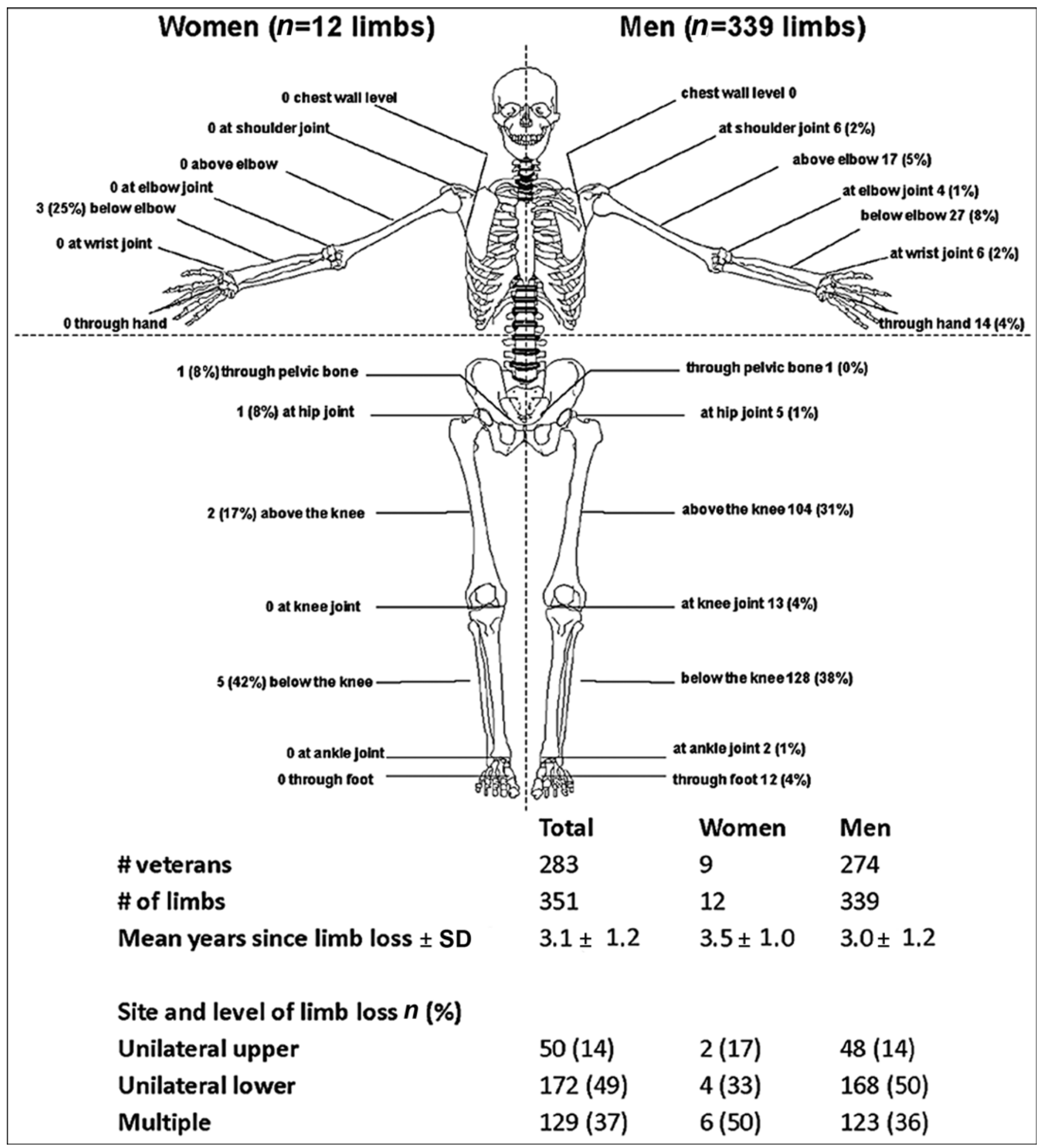

Figure 2.

Level and site of traumatic limb loss among Operation Iraqi Freedom/Operation Enduring Freedom women and men veterans and servicemembers. 
Table 3.

Combat-related injuries among Operation Iraqi Freedom/Operation Enduring Freedom servicemembers and veterans by sex. Data presented as percent.

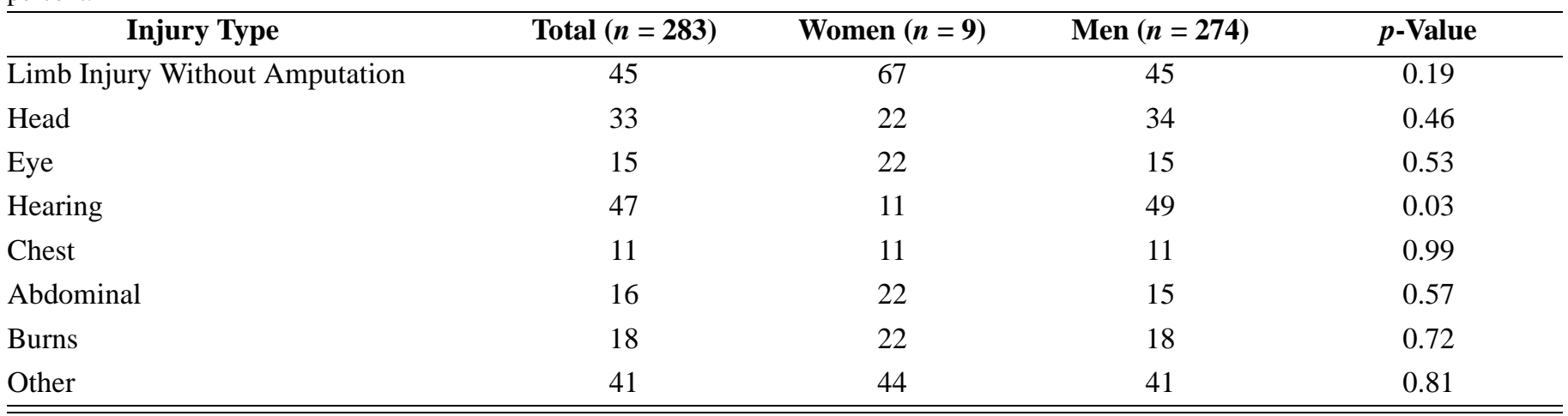

Table 4.

Prosthetic device receipt, rejection, and replacement in Operation Iraqi Freedom/Operation Enduring Freedom servicemembers and veterans by sex. Data presented as mean \pm standard deviation.

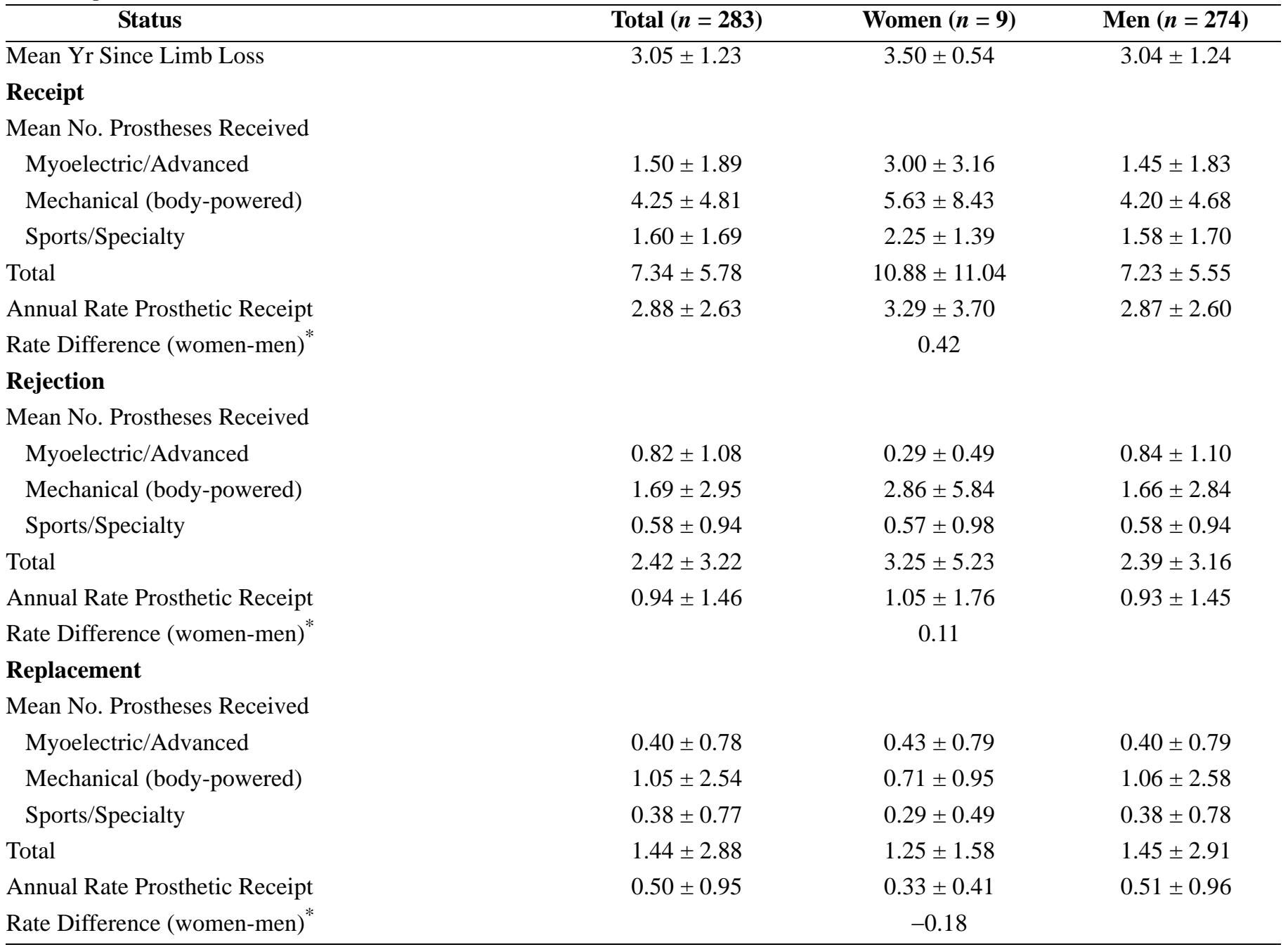

*No. prostheses per year.

No. $=$ number. 
of $7.5 \mathrm{yr}$ following trauma-related limb loss [11]. Importantly, the average length of time from limb loss in our study was $3 \mathrm{yr}$, approximately half that in the study by Pezzin et al., and it is possible that these differences might only become apparent at a longer time after limb loss or might not be present in a veteran population.

Interestingly, compared with men, women in our study reported higher rates of prosthesis receipt and rejection, but lower rates of prosthesis replacement. The higher rates of receipt may be partially a reflection of the higher rejection rates, but may also represent women's need for a larger number of prostheses to accommodate different styles of footwear necessary for different roles (e.g., work, home, physical activity). In a survey of 400 individuals with diabetes, Reiber et al. found that compared with men, women owned more pairs of shoes (8 vs 6) [15], and the larger variety of shoes worn by women, with potentially different heel heights, may require extra prostheses for those with lower-limb loss. The larger overall number of prostheses used by women might also result in lower replacement rates because of lower rates of usage of any given prosthetic device.

Strengths of this study include the use of standardized questions regarding prosthesis usage, collection of detailed information regarding health status and comorbid conditions, and a favorable response rate (59\%). Additionally, this is the first report comparing the health status, prevalence of comorbid conditions, and prosthesis use of men and women veterans and servicemembers with traumatic limb loss. A primary limitation of this study was that women were only 3 percent of the sample. Due to the small number of women in the sample, we had limited ability to conduct more complex analyses and had low power to detect differences in health status, comorbidity, and prosthesis use between men and women with traumatic limb loss. Despite this, we did observe some key differences that may inform provision of care for women amputees as well as drive future research in this population. Finally, information on comorbidities was all self-reported, and we were unable to verify this information in the patient medical records.

\section{CONCLUSIONS}

Given the rapidly increasing number of women servicemembers and veterans [5] and their increased exposure to combat [31], the number of women veterans and servicemembers with traumatic limb loss may be expected to grow, and little is known regarding their health and healthcare needs. We found that compared with men, women with traumatic limb loss had similarly high levels of persistent physical and mental health conditions. Both men and women with traumatic limb loss reported extremely high levels of migraine headaches, with women reporting an approximately threefold higher prevalence of migraine than men. Compared with men, women also had higher rates of prosthesis receipt and rejection, but lower rates of replacement. These findings highlight some potential issues specific to women veterans, which may require additional clinical attention. The findings may also be useful for informing qualitative studies aimed at understanding the experiences and needs of women servicemembers and veterans with traumatic limb loss.

\section{ACKNOWLEDGMENTS}

\section{Author Contributions:}

Analysis and interpretation of data: J. G. Katon.

Drafting of manuscript: J. G. Katon.

Obtained funding for original survey: G. E. Reiber.

Conceived of and designed original survey: G. E. Reiber.

Critical revision of manuscript for important intellectual content:

G. E. Reiber.

Administrative, technical, and material support: G. E. Reiber.

Study supervision: G. E. Reiber.

Final approval of manuscript: J. G. Katon, G. E. Reiber.

Financial Disclosures: The authors have declared that no competing interests exist.

Funding/Support: This material was based on work supported by the VA Office of Research and Development, Health Services Research and Development (grant IRR 05-2444), a Senior Career Scientist Award to Dr. Reiber (grant RCS 98-353), and a Postdoctoral Fellowship to Dr. Katon (grant TPP 61-026).

Institutional Review: The study received human subjects approval from the University of Washington, Seattle, Washington; VA Puget Sound Health Care System, Seattle, Washington; and Madigan Army Medical Center, Tacoma, Washington.

Participant Follow-Up: The authors have no plans to notify the study subjects of the publication of this article because of a lack of contact information.

Additional Contributions: The authors would like to thank Jeff Rodenbaugh for his help with the data management and analysis. Disclaimer: The views expressed in this article are those of the authors and do not necessarily reflect the position or policy of the VA. 


\section{REFERENCES}

1. Reiber GE, McFarland LV, Hubbard S, Maynard C, Blough DK, Gambel JM, Smith DG. Servicemembers and veterans with major traumatic limb loss from Vietnam war and OIF/ OEF conflicts: survey methods, participants, and summary findings. J Rehabil Res Dev. 2010;47(4):275-97.

[PMID:20803399]

http://dx.doi.org/10.1682/JRRD.2010.01.0009

2. Pasquina PF. DOD paradigm shift in care of servicemembers with major limb loss. J Rehabil Res Dev. 2010; 47(4):xi-xiv. [PMID:20803395] http://dx.doi.org/10.1682/JRRD.2009.04.0059

3. Sigford BJ. Paradigm shift for VA amputation care. J Rehabil Res Dev. 2010;47(4):xv-xix. [PMID:20803396] http://dx.doi.org/10.1682/JRRD.2009.02.0020

4. Horgan O, MacLachlan M. Psychosocial adjustment to lower-limb amputation: a review. Disabil Rehabil. 2004; 26(14-15):837-50. [PMID:15497913] http://dx.doi.org/10.1080/09638280410001708869

5. Goldzweig CL, Balekian TM, Rolón C, Yano EM, Shekelle PG. The state of women veterans' health research. Results of a systematic literature review. J Gen Intern Med. 2006;21(Suppl 3):S82-92. [PMID:16637952] http://dx.doi.org/10.1111/j.1525-1497.2006.00380.x

6. Hirsh AT, Dillworth TM, Ehde DM, Jensen MP. Sex differences in pain and psychological functioning in persons with limb loss. J Pain. 2010;11(1):79-86.

[PMID:19734105] http://dx.doi.org/10.1016/j.jpain.2009.06.004

7. Singh R, Hunter J, Philip A, Tyson S. Gender differences in amputation outcome. Disabil Rehabil. 2008;30(2):122-25. [PMID:17852206] http://dx.doi.org/10.1080/09638280701254095

8. Shukla GD, Sahu SC, Tripathi RP, Gupta DK. A psychiatric study of amputees. Br J Psychiatry. 1982;141:50-53. [PMID:7116072] http://dx.doi.org/10.1192/bjp.141.1.50

9. Rybarczyk BD, Nyenhuis DL, Nicholas JJ, Schulz R, Alioto RJ, Blair C. Social discomfort and depression in a sample of adults with leg amputations. Arch Phys Med Rehabil. 1992;73(12):1169-73. [PMID:1463382]

10. Kashani JH, Frank RG, Kashani SR, Wonderlich SA, Reid JC. Depression among amputees. J Clin Psychiatry. 1983; 44(7):256-58. [PMID:6863225]

11. Pezzin LE, Dillingham TR, MacKenzie EJ. Rehabilitation and the long-term outcomes of persons with trauma-related amputations. Arch Phys Med Rehabil. 2000;81(3):292300. [PMID:10724073] http://dx.doi.org/10.1016/S0003-9993(00)90074-1

12. O’Toole DM, Goldberg RT, Ryan B. Functional changes in vascular amputee patients: evaluation by Barthel Index,
PULSES profile and ESCROW scale. Arch Phys Med Rehabil. 1985;66(8):508-11. [PMID:4026551]

13. Furst L, Humphrey M. Coping with the loss of a leg. Prosthet Orthot Int. 1983;7(3):152-56. [PMID:6647011]

14. Murray CD, Fox J. Body image and prosthesis satisfaction in the lower limb amputee. Disabil Rehabil. 2002;24(17): 925-31. [PMID:12519488] http://dx.doi.org/10.1080/09638280210150014

15. Reiber GE, Smith DG, Wallace CM, Vath CA, Sullivan K, Hayes S, Yu O, Martin D, Maciejewski M. Footwear used by individuals with diabetes and a history of foot ulcer. J Rehabil Res Dev. 2002;39(5):615-22. [PMID:17642026]

16. Ware J, Snow K, Kosinski M, Gandek B. SF-36 Health Survey: Manual and interpretation guide. Boston (MA): The Health Institute, New England Medical Center; 1993.

17. DeSalvo KB, Fan VS, McDonell MB, Fihn SD. Predicting mortality and healthcare utilization with a single question. Health Serv Res. 2005;40(4):1234-46. [PMID:16033502] http://dx.doi.org/10.1111/j.1475-6773.2005.00404.x

18. Gallagher P, MacLachlan M. Psychological adjustment and coping in adults with prosthetic limbs. Behav Med. 1999; 25(3):117-24. [PMID:10640225] http://dx.doi.org/10.1080/08964289909596741

19. Williamson GM, Schulz R, Bridges MW, Behan AM. Social and psychological factors in adjustment to limb amputations. J Soc Behav Pers. 1994;9:249-68.

20. Murray CD. An interpretative phenomenological analysis of the embodiment of artificial limbs. Disabil Rehabil. 2004;26(16):963-73. [PMID:15371044] http://dx.doi.org/10.1080/09638280410001696764

21. Lipton RB, Stewart WF, Diamond S, Diamond ML, Reed M. Prevalence and burden of migraine in the United States: data from the American Migraine Study II. Headache. 2001;41(7):646-57. [PMID:11554952] http://dx.doi.org/10.1046/j.1526-4610.2001.041007646.x

22. Lipton RB, Bigal ME, Diamond M, Freitag F, Reed ML, Stewart WF; AMPP Advisory Group. Migraine prevalence, disease burden, and the need for preventive therapy. Neurology. 2007;68(5):343-49. [PMID:17261680] http://dx.doi.org/10.1212/01.wnl.0000252808.97649.21

23. Theeler BJ, Mercer R, Erickson JC. Prevalence and impact of migraine among US Army soldiers deployed in support of Operation Iraqi Freedom. Headache. 2008;48(6):876-82. [PMID:18549370] http://dx.doi.org/10.1111/j.1526-4610.2008.01159.x

24. MacGregor EA, Rosenberg JD, Kurth T. Sex-related differences in epidemiological and clinic-based headache studies. Headache. 2011;51(6):843-59. [PMID:21631472] http://dx.doi.org/10.1111/j.1526-4610.2011.01904.x

25. Sumelahti M-L, Huhtala H, Mauna P. Women and men have different migraine profiles. Suom Laakaril. 2008;39: 3173-77. 
26. Celentano DD, Linet MS, Stewart WF. Gender differences in the experience of headache. Soc Sci Med. 1990;30(12): 1289-95. [PMID:2367875] http://dx.doi.org/10.1016/0277-9536(90)90309-G

27. Jankosky CJ, Hooper TI, Granado NS, Scher A, Gackstetter GD, Boyko EJ, Smith TC; Millennium Cohort Study Team. Headache disorders in the millennium cohort: epidemiology and relations with combat deployment. Headache. 2011;51(7):1098-1111. [PMID:21675968] http://dx.doi.org/10.1111/j.1526-4610.2011.01914.x

28. Hoge CW, McGurk D, Thomas JL, Cox AL, Engel CC, Castro CA. Mild traumatic brain injury in U.S. Soldiers returning from Iraq. N Engl J Med. 2008;358(5):453-63. [PMID:18234750] http://dx.doi.org/10.1056/NEJMoa072972

29. Diener HC, Tfelt-Hansen P. Headache associated with chronic use of substances. In: Olesen J, Tfelt-Hansen P, editors. The headache. New York (NY): Raven Press; 1993. p. 721-27.

30. Kooijman CM, Dijkstra PU, Geertzen JH, Elzinga A, van der Schans CP. Phantom pain and phantom sensations in upper limb amputees: an epidemiological study. Pain.
2000;87(1):33-41. [PMID:10863043]

http://dx.doi.org/10.1016/S0304-3959(00)00264-5

31. Zinzow HM, Grubaugh AL, Monnier J, Suffoletta-Maierle S, Frueh BC. Trauma among female veterans: a critical review. Trauma Violence Abuse. 2007;8(4):384-400. [PMID:17846179]

http://dx.doi.org/10.1177/1524838007307295

Submitted for publication January 9, 2012. Accepted in revised form June 7, 2012.

This article and any supplemental material should be cited as follows:

Katon JG, Reiber GE. Major traumatic limb loss among women veterans and servicemembers. J Rehabil Res Dev. 2013;50(2):173-82.

http://dx.doi.org/10.1682/JRRD.2012.01.0007

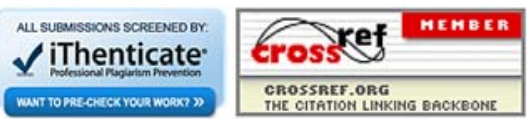

